\title{
PENERAPAN METODE BERNYANYI UNTUK MENINGKATKAN KEMAMPUAN CUCI TANGAN PADA ANAK USIA SEKOLAH
}

\author{
Sri Aminingsih, Warsini \\ AKPER PANTI KOSALA SURAKARTA, Sukoharjo, Jawa Tengah, Indonesia
}

\begin{abstract}
Abstrak
Latar belakang : kebiasaan cuci tangan yang benar sangat penting. Namun menurut Badan Pusat Statistik kebiasaan cuci tangan yang benar di Provinsi Jawa Tengah belum maksimal yaitu sebesar 53,6\%. Dari observasi yang dilakukan peneliti di Dusun Ngegot Kabupaten Karanganyar masih terlihat bahwa beberapa anak saat membeli jajanan langsung mengonsumsi jajanan tersebut tanpa mencuci tangan terlebih dahulu, padahal masing-masing rumah sudah menyediakan tempat cuci tangan di depan rumah.

Tujuan : untuk mengetahui pengaruh penerapan metode bernyanyi terhadap kemampuan cuci tangan pada anak usia sekolah.

Metode : penelitian ini merupakan penelitian eksperimental dengan desain pre-post experimental control design untuk mengetahui pengaruh metode bernyanyi dalam meningkatkan kemampuan cuci tangan anak usia sekolah.

Hasil : hasil pretest pada kelompok perlakuan terdapat $93,3 \%$ anak yang tidak mampu melakukan cuci tangan dengan benar dan $6,7 \%$ anak yang mampu melakukan cuci tangan dengan benar dan hasil posttest terdapat $20 \%$ anak yang tidak mampu melakukan cuci tangan dengan benar dan $80 \%$ anak yang mampu melakukan cuci tangan dengan benar. Sedangkan pada kelompok kontrol hasil pretest terdapat 93,3\% anak yang tidak mampu melakukan cuci tangan dengan benar dan $6,7 \%$ anak yang mampu melakukan cuci tangan dengan benar dan hasil posttest terdapat $60 \%$ anak yang tidak mampu melakukan cuci tangan dengan benar dan $40 \%$ anak yang mampu melakukan cuci tangan dengan benar. Dengan menggunakan Uji Mann Whitney diperoleh hasil $p=0,028$.

Kesimpulan : penerapan metode bernyanyi efektif untuk meningkatkan kemampuan mencuci tangan.
\end{abstract}

Kata kunci : kemampuan mencuci tangan, metode bernyanyi, penerapan

\section{APPLICATION OF SINGING METHODS TO IMPROVE HANDWASHING ABILITY IN SCHOOL AGE CHILDREN}

\author{
Sri Aminingsih, Warsini
}

\begin{abstract}
Background : correct hand washing habits are very important. However, according to the Central Statistics Agency, the correct habit of washing hands in Central Java Province is not maximal, namely at 53.6\%. From observations made by researchers in Ngegot, Karanganyar Regency, it is still seen that some children when buying snacks immediately consume these snacks without washing their hands first, even though each house has provided a place to wash their hands in front of the house.

The aims of the study : this is to determine the effect of the singing method on the ability to wash hands in school age children.

Method. This research is an experimental study with a pre-post experimental control design to determine the effect of the singing method in improving the ability of school age children to wash their hands.

Result : the pretest results in the treatment group were $93.3 \%$ of children who were unable to wash their hands properly and $6.7 \%$ of children who were able to wash their hands properly and posttest results there were $20 \%$ of children who were unable to wash their hands properly and $80 \%$ children who are able to wash their hands properly.
\end{abstract}


Whereas in the control group, the pretest results were $93.3 \%$ of the children who were unable to wash their hands properly and $6.7 \%$ of the children who were able to wash their hands properly and the posttest results there were $60 \%$ of the children who were unable to wash their hands properly and $40 \%$ of children who are able to wash their hands properly. By using the Mann Whitney test the result was $p=0.028$.

Conclusion : the application of the singing method is effective in improving the ability to wash hands.

Key words: ability to wash hands, singing method, application

Korespondensi: Sri Aminingsih. AKPER PANTI KOSALA SURAKARTA. Jalan Raya Solo-Baki Km. 4 Gedangan, Grogol, Sukoharjo, Jawa Tengah. Email: sraminingsih.75@gmail.com.

\section{PENDAHULUAN}

Cuci tangan yang benar sangat penting untuk diterapkan pada anak. Menurut Badan Pusat Statistik (2018), Provinsi Jawa Tengah mempunyai kebiasaan cuci tangan yang benar sebanyak 53,6 \%. Sedangkan di daerah Karanganyar mempunyai kebiasaan cuci tangan yang benar sebanyak 53,4\%. Menurut World Health Organization (WHO) yang dikutip oleh Gunawan dan Yulita (2020), cuci tangan adalah langkah awal yang efektif mencegah segala penyakit, seperti infeksi saluran pencernaan, dan penyakit pernafasan. Menurut Maryunani (2013), belum dibudayakannya di keluarga atau rumah tangga menjadi penyebab kebiasaan cuci tangan yang kurang benar.

Menurut Proverawati dan Rahmawati (2012), cuci tangan berfungsi untuk menghilangkan atau mengurangi mikroorganisme yang menempel di tangan. Cuci tangan harus dilakukan dengan menggunakan air bersih dan sabun. Air yang tidak bersih banyak mengandung kuman dan bakteri penyebab penyakit. Bila digunakan kuman berpindah ke tangan dan dengan cepat masuk ke dalam tubuh sehingga bisa menimbulkan penyakit. Sedangkan sabun dapat membersihkan kotoran dan membunuh kuman karena tanpa sabun, maka kotoran dan kuman masih tertinggal di tangan.

Menurut Ghofar (2012), hal-hal yang harus diperhatikan dalam mencuci tangan yang tepat adalah teliti, dan melakukan kegiatan cuci tangan minimal 1 menit untuk mencegah infeksi silang melalui tangan. Mencuci tangan yang benar harus ditanamkan sejak masih anak-anak. Untuk menghindari anak mencuci dengan terburu-buru dan salah, bisa dilakukan sambil bernyanyi (Lusia, 2015). Anak pada umumnya sangat menyukai bernyanyi sambil bertepuk tangan. Dengan menggunakan nyanyian dalam setiap pembelajaran anak akan mampu merangsang perkembangannya, khususnya dalam berbahasa dan berinteraksi dengan lingkungannya (Fadlillah, 2014).

Teori di atas didukung oleh penelitian yang dilakukan oleh Suwanti dan Krisbiantoro (2019), yang berjudul pengaruh pendidikan kesehatan dengan metode bernyanyi terhadap perilaku cuci tangan yang benar dengan metode penelitian yang digunakan adalah pre-experimental. Hasil dari penelitian ini adalah menunjukkan bahwa terdapat pengaruh pendidikan kesehatan dengan metode bernyanyi terhadap perilaku cuci tangan yang benar.

Penelitian serupa juga dilakukan oleh Fadhmasari, et al., (2016), yang berjudul efektivitas demonstrasi dan bernyanyi lagu cuci tangan terhadap kemampuan cuci tangan pada anak prasekolah di TK PGRI 38 Semarang metode penelitian yang digunakan adalah quasi experiment. Didapatkan hasil $p$ value $=0,540$, dapat disimpulkan tidak ada perbedaan yang signifikan sesudah diberikan tindakan demonstrasi dan bernyanyi lagu cuci tangan, maka intervensi ini dapat meningkatkan kemampuan cuci tangan pada anak prasekolah di TK PGRI 38 Semarang. 
Menurut Fadlillah (2014), metode bernyanyi mampu menumbuhkan minat dan menguatkan daya tarik pembelajaran, menciptakan proses pembelajaran lebih humanis dan menyenangkan, sebagai jembatan dalam mengingat materi pembelajaran, dan mendorong motivasi belajar. Teori ini didukung oleh penelitian yang di lakukan oleh Prajawati, et al., (2014), didapatkan hasil uji statistik menggunakan uji statistik Wilcoxon Signed Rank Test didapatkan nilai $\mathrm{p} \leq \mathrm{a}$ $(p=0,000)$, maka $\mathrm{H} 1$ diterima artinya metode bernyanyi berpengaruh terhadap tindakan cuci tangan.

Menurut Akbar (2020), metode bernyanyi memiliki kelebihan, yaitu dapat merangsang imajinasi anak, dapat memicu kreativitas, dan memberi stimulus yang cukup kuat terhadap otak sehingga mendorong kognitif anak dengan cepat. Teori tersebut didukung oleh penelitian yang dilakukan oleh Idayanti, et al., (2017), dengan metode penelitian yang digunakan adalah quasy experiment bentuk pretest dan posttest mendapatkan hasil ada pengaruh pendidikan kesehatan dengan penerapan metode bernyanyi terhadap kemampuan mencuci tangan pada kelompok kontrol di Siswa Kelas A1 Di RA Muslimat Darul Faizin I di dapatkan data pada kelompok perlakuan mencuci tangan $\rho=0,000<$ $\alpha=0,05$.

Penelitian setipe dilakukan oleh Indriani, et al., (2019), yang berjudul metode senam cuci tangan menurut UNICEF pada anak usia prasekolah di Kecamatan Puring metode penelitian yang digunakan adalah pretest, ceramah, diskusi dan posttest. Hasil penelitiannya ada peningkatan pengetahuan teknik cuci tangan pada anak usia prasekolah di Paud Citra Mulia Desa Kedaleman Wetan dan Paud Cahaya Berlian Desa Kedaleman Kulon Kecamatan Puring.

Dari pengamatan yang dilakukan peneliti di Dusun Ngegot masih terlihat beberapa anak pada saat membeli jajanan keliling langsung mengkonsumsi jajanan tersebut tanpa melakukan cuci tangan terlebih dahulu meskipun di setiap rumah sudah disediakan tempat untuk cuci tangan di depan rumah.

Penelitian ini adalah replikasi dari penelitian sebelumnya meskipun ada sedikit perbedaan yaitu tempat dilakukan penelitian dan usia responden yang digunakan berbeda dengan penelitian sebelumnya yaitu pada anak usia sekolah khususnya usia 6-9 tahun. Berdasarkan latar belakang masalah di atas maka peneliti tertarik untuk melakukan penelitian tentang penerapan metode bernyanyi untuk meningkatkan kemampuan cuci tangan pada anak usia sekolah.

\section{TUJUAN PENELITIAN}

Untuk mengetahui pengaruh penerapan metode benyanyi terhadap kemampuan cuci tangan pada anak usia sekolah khususnya pada usia 6-9 tahun.

\section{DESAIN PENELITIAN}

Penelitian ini merupakan penelitian eksperimental dengan rancangan pre post exsperimental control design untuk mengetahui pengaruh metode bernyanyi untuk meningkatkan kemampuan cuci tangan pada anak usia sekolah. Kelompok kontrol dalam penelitian ini adalah anak yang diajarkan mencuci tangan menggunakan nyanyian sedangkan kelompok kontrol merupakan kelompok anak yang diajarkan mencuci tangan dengan metode klasik tanpa menggunakan nyanyian.

\section{POPULASI, SAMPEL, DAN TEKNIK SAMPLING}

Populasi pada penelitian ini adalah anak usia sekolah yaitu 6-9 tahun di dusun Ngegot RW XII (kelompok kontrol) dan RW XIII (kelompok perlakuan) Selokaton Kabupaten Karanganyar pada bulan Januari sampai Maret 2021. Teknik sampling yang digunakan dalam penelitian ini adalah dengan teknik sampling jenuh. 
HASIL PENELITIAN

Tabel 1.

Distribusi Frekuensi Berdasarkan Umur dan Jenis Kelamin

\begin{tabular}{lcccc}
\hline Karakteristik & \multicolumn{2}{c}{ Kelompok Perlakuan } & \multicolumn{2}{c}{ Kelompok Kontrol } \\
\cline { 2 - 5 } Responden & $\mathrm{f}$ & $\%$ & $\mathrm{f}$ & $\%$ \\
\hline Umur & 3 & 20 & 0 & 0 \\
6 & 6 & 40 & 4 & 6,67 \\
7 & 1 & 6,7 & 4 & 6,67 \\
8 & 5 & 33,3 & 7 & 6,66 \\
9 & & & & \\
Jenis kelamin & 3 & 6,67 & 6 & 40 \\
Laki-laki & 2 & 3,33 & 9 & 60 \\
Perempuan & 15 & 100 & 15 & 100 \\
Jumlah & & & & \\
\hline
\end{tabular}

Dari tabel di atas diperoleh informasi bahwa responden dengan kelompok umur terbanyak adalah umur 9 tahun terdapat 12 anak. Sedangkan jenis kelamin laki-laki sebanyak 19 dan perempuan sebanyak 11.

Tabel 2.

Hasil Analisa Statistik

\begin{tabular}{lc}
\hline Kemampuan Cuci Tangan & Post Tes \\
\hline Kelompok Perlakuan & $3(20 \%)$ \\
Tidak Mampu & $12(80 \%)$ \\
Mampu &
\end{tabular}

Wilcoxon Signed Ranks Test

$$
p=0,001
$$

Kelompok kontrol

Tidak mampu

$9(60 \%)$

Mampu

$6(40 \%)$

Wilcoxon Signed Ranks Test

$$
\mathrm{p}=0,025
$$

Mann Whitney Test

$$
\mathrm{P}=0,028
$$

Pada kelompok perlakuan
pada saat dilakukan pretest
terdapat $14 \quad(93,3 \%)$ anak yang
tidak mampu melakukan cuci
tangan dengan benar dan $1(6,7 \%)$
anak mampu melakukan cuci
tangan dengan benar, sedangkan
saat dilakukan posttest dengan
penerapan metode bernyanyi

terdapat $3(20 \%)$ anak tidak mampu melakukan cuci tangan dengan benar dan terdapat $12(80 \%)$ anak mampu melakukan cuci tangan dengan benar. 
Pada kelompok kontrol pada saat dilakukan pretest terdapat 14 $(93,3 \%)$ anak yang tidak mampu melakukan cuci tangan dengan benar dan 1 (6,7\%) anak mampu melakukan cuci tangan dengan benar, sedangkan saat dilakukan posttest tanpa penerapan metode bernyanyi terdapat $9(60 \%)$ anak tidak mampu melakukan cuci tangan dengan benar dan terdapat $6(40 \%)$ anak mampu melakukan cuci tangan dengan benar.

Setelah dilakukan uji Wilcoxon Signed Ranks Test didapatkan hasil signifikansi pada kelompok perlakuan untuk kemampuan cuci tangan sebelum dan sesudah penerapan metode bernyanyi yaitu $\mathrm{p}=0,001$ sedangkan hasil uji Wilcoxon Signed Ranks Test pada kelompok kontrol antara pretest dan posttest diperoleh hasil $p=0,025$.

Pengaruh kemampuan cuci tangan dengan penerapan metode bernyanyi pada kelompok perlakuan dan kelompok kontrol dilakukan analisa statistik dengan menggunakan uji Mann Whitney Test didapatkan hasil $\mathrm{p}=0,028$. Penerapan metode bernyanyi efektif untuk meningkatkan kemampuan cuci tangan.

\section{PEMBAHASAN}

Berdasarkan analisa statistik diperoleh hasil bahwa penerapan metode bernyanyi efektif untuk meningkatkan kemampuan cuci tangan. Dalam penelitian ini terbagi menjadi dua kelompok yaitu kelompok perlakuan terdiri dari 15 anak yang diobservasi kemampuan cuci tangan dengan penerapan metode bernyanyi sedangkan kelompok yang lain yaitu kelompok kontrol yang terdiri dari 15 anak diobservasi kemampuan cuci tangan tanpa penerapan metode bernyanyi.

Pada kelompok perlakuan saat dilakukan pretest terdapat 14 $(93,3 \%)$ anak yang tidak mampu melakukan cuci tangan dengan benar sedangkan kelompok kontrol terdapat $14 \quad(93,3 \%)$ anak yang tidak mampu melakukan cuci tangan dengan benar. Dari data awal ini baik kelompok perlakuan ataupun kelompok kontrol memiliki kesamaan yaitu hanya 1 anak yang mampu melakukan cuci tangan dengan benar. Sedangkan setelah dilakukan edukasi dengan penerapan metode bernyanyi pada kelompok perlakuan jumlah anak yang mampu melakukan cuci tangan dengan benar terdapat peningkatan yaitu 12 anak, sedangkan pada kelompok kontrol setelah dilakukan edukasi dengan metode klasik yaitu ceramah dan demonstrasi kemampuan anak untuk melakukan cuci tangan dengan benar terdapat 6 anak. Hasil ini menunjukkan bahwa dengan penerapan metode bernyanyi pada kelompok perlakuan kemampuan anak dalam melakukan cuci tangan lebih banyak bila dibandingkan kemampuan cuci tangan anak pada kelompok kontrol yang menggunakan metode klasik bahkan anak yang tidak mampu cuci tangan dengan benar jumlahnya lebih banyak yaitu 9 anak. Setelah dilakukan uji Wilcoxon Signed Ranks Test didapatkan hasil signifikansi pada kelompok perlakuan untuk kemampuan cuci tangan sebelum dan sesudah penerapan metode bernyanyi yaitu $p=0,001$ sedangkan hasil uji Wilcoxon Signed Ranks Test pada kelompok kontrol antara pretest dan posttest diperoleh hasil $p=0,025$. Dari hasil tersebut dapat diartikan bahwa dengan penerapan metode bernyanyi kemampuan anak dalam melakukan cuci tangan lebih optimal.

Hasil penelitian ini sesuai dengan beberapa teori menurut World Health Organization (WHO) sebagaimana dikutip oleh Gunawan dan Yulita (2020), cuci tangan 
adalah langkah awal yang efektif mencegah segala penyakit, seperti infeksi saluran pencernaan, dan penyakit pernafasan. Sedangkan menurut Mubarak, et al. (2015), mencuci tangan adalah kegiatan membersihkan bagian telapak tangan, punggung tangan, dan jari tangan agar bersih dari kotoran dan membunuh kuman penyebab penyakit yang merugikan kesehatan manusia. Dalam proses pembelajaran bahwa saat anak memperoleh hal baru akan lebih mudah diterima apabila hal baru tersebut disampaikan dengan beberapa metode seperti metode melengkapi kata, bertanya, bernyanyi, bercerita dan yang lainnya. Adapun dalam penelitian ini peneliti memilih penerapan metode bernyanyi untuk menyampaikan hal yang baru pada anak yaitu kemampuan cuci tangan dengan menggunakan penerapan metode bernyanyi. Menurut Kurniawan, et al. (2017), perkembangan bahasa yang baik menunjukkan perkembangan kognitif anak yang baik. Sebab, melalui bahasa anak anak bisa memahami ilmu pengetahuan dan menyampaikan gagasan kognitifnya. Menurut Akbar (2020), dalam pembelajaran dengan metode bernyanyi berarti menciptakan pembelajaran dengan menggunakan syair yang dilagukan dan sesuai dengan materi yang diajarkan. Dengan bernyanyi dapat menciptakan suasana belajar menjadi riang dan bergairah sehingga perkembangan anak dapat terstimulasi secara optimal dan dapat mengembangkan seluruh aspek dalam diri anak yang meliputi fisik - motorik, sosial, emosional, intelektual, bahasa, seni, serta moral dan agama. Paparan teori ini sesuai dengan penelitian yang dilakukan oleh Faijah dan Nurlaila (2019), dengan kesimpulan penerapan metode bernyanyi terbukti dapat meningkatkan kemampuan cuci tangan pada anak. Penelitian setipe dilakukan oleh Juliawan, et al. (2019), dengan hasil uji paired-t didapatkan nilai $p=$ 0,000 , artinya ada pengaruh pendidikan kesehatan dengan bernyanyi lagu cuci tangan terhadap tindakan mencuci tangan pada anak usia pra sekolah.

Pada penelitian ini setelah dilakukan uji Wilcoxon Signed Ranks Test didapatkan hasil signifikansi pada kelompok perlakuan untuk kemampuan cuci tangan sebelum dan sesudah penerapan metode bernyanyi yaitu $\mathrm{p}=0,001$ sedangkan hasil uji Wilcoxon Signed Ranks Test pada kelompok kontrol antara pretest dan posttest diperoleh hasil $p=0,025$. Dari hasil ini menunjukkan adanya perbedaan kemampuan cuci tangan anak antara kelompok perlakuan dengan penerapan metode bernyanyi dan kelompok kontrol yang tidak menggunakan metode bernyanyi. Kemampuan cuci tangan anak pada kelompok perlakuan lebih baik dari pada kemampuan cuci tangan anak pada kelompok kontrol. Hasil penelitian ini sesuai dengan penelitian yang dilakukan oleh Luthfi, et al. (2020), yang menunjukkan adanya pengaruh gerak dan nyanyi dengan alat bantu audio visual aids dalam membantu pemahaman siswa tentang bagaimana cuci tangan yang benar. Pada penelitian ini penerapan metode bernyanyi dalam upaya meningkatkan kemampuan cuci tangan lebih efektif dibandingkan dengan metode klasik yaitu dengan ceramah dan demonstrasi yang ditunjukkan hasil uji Mann Whitney Test diperoleh hasil $p=0,028$. penerapan metode bernyanyi efektif untuk meningkatkan kemampuan cuci tangan. Menurut Kyle dan Carman (2015), anak usia sekolah antara 6 dan 12 tahun, mengalami waktu pertumbuhan fisik progresif yang lambat, sedangkan 
kompleksitas pertumbuhan sosial dan perkembangan mengalami percepatan dan meningkat. Fokus dunia mereka berkembang dari keluarga ke guru, teman sebaya, dan pengaruh luar lainnya (misal, pelatih dan media). Jadi manfaat menyanyi membawa energi positif yang disalurkan anak sehingga semua aspek perkembangan anak dapat optimal dan dapat membawa suasana yang menyenangkan dalam proses belajar anak. Menurut Rachmawati sebagaimana dikutip oleh Fadlillah (2014), kegiatan menyanyi dengan menggunakan musik akan dapat mengembangkan pengetahuan dan keterampilan. Teori ini sejalan dengan penelitian yang dilakukan oleh Apriany (2012), dengan hasil uji t didapatkan ada perbedaan signifikan perilaku cuci tangan sesudah diberikan pendidikan kesehatan ( $p$ value 0,001 ).

Hasil penelitian ini sesuai dengan paparan teori di atas, dimana penerapan metode bernyanyi sangat berdampak secara optimal untuk mengasah kemampuan anak dalam melakukan cuci tangan, karena aktivitas ini bagi anak cukup menyenangkan sehingga anak tidak mengalami kesulitan dalam mengingat dan mempraktikkan tahap demi tahap langkah cuci tangan yang benar. Pada kelompok perlakuan terdapat peningkatan jumlah anak yang mampu melakukan cuci tangan dengan benar yaitu 12 anak setelah dilakukan penerapan metode bernyanyi saat melakukan cuci tangan. Sedangkan pada kelompok kontrol anak yang mampu melakukan cuci tangan tanpa menggunakan penerapan metode bernyanyi dari 1 anak meningkat menjadi 6 anak yang mampu melakukan cuci tangan dengan benar. Dari uraian tersebut dapat dijabarkan bahwa kemampuan anak dalam melakukan cuci tangan dengan penerapan metode bernyanyi lebih efektif bila dibandingkan dengan kemampuan anak yang melakukan cuci tangan tanpa menggunakan penerapan metode bernyanyi. Berdasarkan hasil penelitian terdapat signifikansi sebesar $p=0,028$ penerapan metode bernyanyi efektif untuk meningkatkan kemampuan cuci tangan.

\section{KESIMPULAN}

Hasil penelitian ini diperoleh kesimpulan penerapan metode bernyanyi efektif untuk meningkatkan kemampuan cuci tangan pada anak usia sekolah yaitu 6-9 tahun.

\section{SARAN}

1. Diharapkan bagi petugas kesehatan untuk terus melakukan penyuluhan tentang pentingnya cuci tangan yang benar pada anak-anak dengan metode komunikasi aktif.

2. Diharapkan keluarga mampu meningkatkan peran sertanya dalam memberikan dukungan bagi anak-anak untuk melakukan cuci tangan dengan benar.

\section{DAFTAR PUSTAKA}

Akbar, E. 2020. Metode Belajar Anak Usia Dini. https://books.google.co.id. Diakses pada tanggal 23 Oktober 2020.

Apriany, D. 2012. "Perbedaan Perilaku Mencuci Tangan Sebelum dan Sesudah diberikan Pendidikan Kesehatan pada Anak Usia 45 Tahun". Jurnal Keperawatan Soedirman. 7. Jawa Barat. Diakses pada tanggal 29 Oktober 2020.

Fadamasari, et al. 2016. "Efektivitas Demonstrasi dan Bernyanyi Lagu Cuci Tangan terhadap Kemampuan Cuci Tangan pada Anak Pra Sekolah di TK 
PGRI 38 Semarang”. STIKES Telogorejo Semarang.

Diakses pada tanggal 23 Oktober 2020.

Fadlillah, M., et al. 2014. Edutainment Pendidikan Anak Usia Dini.

https://books.google.co.id.

Diakses pada tanggal 23 Oktober 2020.

Faijah, F. dan Nurlaila. 2019. "Penerapan Metode Bernyanyi untuk Meningkatkan Kemampuan Cuci Tangan pada Anak di TK Mekarsari Ambalresmi”. University Research Colloqium. Sekolah Tinggi IImu Kesehatan Muhammadiyah Gombong. Diakses pada tanggal 23 Oktober 2020.

Gofar, Abdul. 2012. Pedoman Lengkap Keterampilan Perawatan Klinik. Mitra Buku, Yogyakarta.

Gunawan, I.C dan Yulita. 2020. Pedoman Lengkap Keterampilan Perawatan Klinik. Mitra Buku, Yogyakarta.

Guslinda dan K. Rita. 2018. Perpustakaan Nasional Republik Indonesia Katalog dalam Terbitan (KDT) Media Pembelajaran Anak Usia Dini. https://books.google.co.id.

Diakses pada tanggal 23 Oktober 2020.

Idayanti, Titiek, et al. 2017. "Pengaruh Pendidikan Kesehatan dengan Penerapan Metode Bernyanyi Terhadap Kemampuan Mencuci Tangan Pada Siswa Kelas A 1 di RA Muslimat Darul Faizin I Desa Catak Gayam Mojowarno Jombang". Jurnal Nurse and Health. 6. Diakses pada tanggal 23 Oktober 2020.

Indriani, Eni, et al. 2019. "Metode Senam Cuci Tangan Menurut
Unicef Pada Usia Pra Sekolah di Kecamatan Puring". Skripsi. Universitas Muhammadiyah Purworejo. Diakses pada tanggal 23 Oktober 2020.

Juliawan, D.G, Mirayanti, N.K.A, dan Parwati, N.A. 2019. "Pengaruh Pendidikan Kesehatan dengan Bernyanyi Lagu Cuci Tangan Terhadap Tindakan Mencuci Tangan Anak Prasekolah". 3. Departemen Kesehatan Medikal Beda. STIKES Wira Medika, Bali. Diakses pada tanggal 23 Oktober 2020.

Kurniawan, et al. Solutif Parenting 333 Cara Praktis untuk Mewujudkan Anak Cerdas, Kreatif \& Berkarakter. PT Elex Media Komputindo, Jakarta.

Kyle, T. dan S. Carman. 2015. Buku Ajar Keperawatan Pediatri. Edisi II. Vol.1. EGC, Jakarta.

Lusia. 2015. Mengenal Demam dan Perawatannya pada Anak. Airlangga University Press, Surabaya.

Luthfi, F, et al. 2020. "Pengaruh Promosi Cuci Tangan Yang Benar Pada Anak", Jurnal Kesehatan. 11. Fakultas Kesehatan Masyarakat, Universitas Teuku Umar Meulaboh, Aceh. Diakses pada tanggal 11 Januari 2021.

Maryuni, Anik. 2013. Perilaku Hidup Bersih dan Sehat (PHBS). CV. Trans Info Media, Jakarta.

Mubarak, et al. 2015. Buku Ajar IImu Keperawatan Dasar. Salemba Medika, Jakarta.

Prajawati, Yuni Kurnia, et al. 2014. "Meningkatkan Perilaku Cuci Tangan Melalui Metode Bernyanyi". Jurnal Pediomaternal. 3. Diakses pada tanggal 23 Oktober 2020. 
KOsnเn: Jurnal IImu Kesehatan Vol. 9 No.1 Mei 2021

Proverawati, A dan Rahmawati. 2012. Perilaku Hidup bersih dan Sehat. Nuha Medika, Yogyakarta.

Suwanti, lis dan Dika Krisbiantoro. 2019. "Pengaruh Pendidikan Kesehatan Dengan Metode Bernyanyi Terhadap Perilaku Cuci Tangan Yang Benar". Jurnal Keperawatan dan Kebidanan. Diakses 23 Oktober 2020. 